\title{
Stereological analysis of hippocampus in rat treated with chemotherapeutic agent oxaliplatin
}

\author{
J. Sadeghinezhad', I. Amrein ${ }^{2,3}$ \\ ${ }^{1}$ Department of Basic Sciences, Faculty of Veterinary Medicine, University of Tehran, Iran \\ IInstitute of Anatomy, Division of Functional Neuroanatomy, University of Zurich, Switzerland \\ ${ }^{3}$ Department of Health Sciences and Technology, ETH, Zurich, Switzerland
}

[Received: 12 December 2019; Accepted: 27 January 2020]

Background: Oxaliplatin (OX) has been widely used for treatment of colorectal and other cancers. Adverse effect of $O X$ and other anticancer agents on cognition have been reported, but studies on the effects of chemotherapy on brain structure are scarce. This study describes the morphometrical features of the hippocampus structures in rat following OX treatment using design-based stereological methods. Materials and methods: Ten male Wistar rats were randomised into two groups. The rats from OX group received $2.4 \mathrm{mg} / \mathrm{kg}$ OX in vehicle for 5 consecutive days every week for 2 weeks intraperitoneally. Controls received vehicle only. Cavalieri's method and the optical fractionator method were used for volume and neuron estimation, respectively.

Results: Cavalieri's method was used to estimate volume and showed that the volume of the hippocampus was significantly decreased in OX group (31.84 \pm $\left.\pm 1.24 \mathrm{~mm}^{3}\right)$ compared with the vehicle control group $\left(36.95 \pm 3.48 \mathrm{~mm}^{3}\right)$. The optical fractionator method was used to estimate neuron number and showed that the number of neurons in dentate gyrus, cornu ammonis 1 and 3 in OX group $\left(8.147 \pm 2.84 \times 10^{5}, 4.257 \pm 0.59 \times 10^{5}\right.$ and $2.133 \pm 0.22 \times 10^{5}$, respectively) did not differ from those of vehicle control group $\left(7.36 \pm 1.42 \times 10^{5}, 3.521 \pm\right.$ $\pm 0.54 \times 10^{5}$ and $1.989 \pm 0.46 \times 10^{5}$, respectively)

Conclusions: These findings suggested that OX treatment induces loss of hippocampal volume without neuronal loss which might help to clarify the mechanism by which OX affects cognition and to improve preventive treatment strategies. (Folia Morphol 2021; 80, 1: 26-32)

Key words: stereology, hippocampus, oxaliplatin, chemotherapy, rat

\section{INTRODUCTION}

Chemotherapy in many cancer types have increased survival times in patients. However, cognitive dysfunctions, referred to as "chemobrain", such as impairments in attention and concentration, verbal and visual memory and processing speed have been reported after systemic chemotherapy $[7,41]$. There are numerous reports regarding adverse effect of different anticancer agents such as methotrexate
[29, 37, 42, 46], 5-fluorouracil [8, 11], cyclophosphamide [9, 36], doxorubicin [23, 27], paclitaxel [19], vincristine $[5,35]$ and cytosine arabinoside [26] on cognition in human and animal experimental models. Chemotherapy agents, which inhibit tumour cell proliferation, can also effect on non-tumour cell proliferation in the brain [7].

Oxaliplatin (OX) is a third-generation platinum drug which has been widely used alone or with other 
chemotherapeutic agents for treatment of colorectal cancer and other carcinomas including ovarian, breast and lung cancers $[34,40]$. It is able to react with DNA to create DNA intrastrand adducts, which block DNA synthesis and induce apoptosis in cancer cells and rapidly dividing cells [43]. OX induces peripheral neuropathy [38], crosses the blood-brain barrier and accumulates in cerebrospinal and extracellular fluid in the brain $[17,18]$, which indicates that the drug can have a direct effect on brain function and structure. Treatment with OX has been shown to induce cognitive impairment in laboratory animals $[9,10,39]$. Furthermore, cellular damage in the hippocampus has been related to the loss of memory function in rats following OX administration [4, 7]. Other platinum compounds such as cisplatin, have also been reported to produce cognitive dysfunction and central neurological problems $[28,48]$.

The hippocampus, as the key structure in learning and the formation of memory is an appropriate site for investigating the mechanisms involved in some of the cognitive problems arisen by the chemotherapeutic agents [4].

Designed-base stereology enables unbiased and precise quantitative analysis of three-dimensional structures [15]. It is one of the important techniques for the morphometrical evaluation of the hippocampus, which contain important information about the memory function [14]. The morphometrical features of the hippocampus following chemotherapy have not been thoroughly investigated using stereology. Assessment of the effect of OX on hippocampus volume using Cavalieri's method and neuronal number in different regions of the hippocampus using optical disector/fractionator, as a gold standard for efficient, unbiased number estimation in neuroscience, may contribute to evaluate the risks of the treatment and possibly help improve preventive strategies.

\section{MATERIALS AND METHODS}

\section{Animals}

Ten adult (12-15 weeks) male Wistar rats (Pasteur Institute, Tehran, Iran) were used for the experiment. Animals were housed in large acrylic cages with free access to food and water under controlled light $(12 \mathrm{~h}$ light and dark cycle) and temperature $\left(22 \pm 2^{\circ} \mathrm{C}\right)$. The rats were allowed to acclimatise for 1 week before experimentation.

All experimental procedures involving animals in this study were conducted in accordance with the standard guide for the care and use of laboratory animals of the University of Tehran, Tehran, Iran.

\section{Drug administration}

Rats were randomly divided into OX-treated and vehicle control groups. The rats from OX group received $2.4 \mathrm{mg} / \mathrm{kg}$ OX dissolved in $5 \%$ glucose solution (vehicle) for 5 consecutive days per week for 2 weeks intraperitoneally (IP) and the vehicle control was administrated $5 \%$ glucose solution. The chosen dose of OX was in accordance with that commonly used for neurotoxic evaluation of the agent in previous animal studies [4].

\section{Tissue sampling and stereological methods}

Rats were euthanized 21 days after treatment using thiopental $(50 \mathrm{mg} / \mathrm{kg}$ IP). Then, transcardial perfusion fixation of the animals was done using $10 \%$ formalin. The brains were removed and the left hemisphere of each animal was fixed in same fixative, dehydrated and embedded in glycol methacrylate (Technovit 7100, Heraeus Kulzer GmbH, Wehrheim/Ts, Germany) according to the manufacturer's instructions.

Embedded brains were cut frontally using a rotary microtome with 20 micrometre thickness. Every $20^{\text {th }}$ section was collected using the principle of systematic uniform random sampling, which is known as the section sampling fraction ( $s$ f $=1 / 20$ ). On average, this sampling scheme provided 13 (11-15) sections per animal. Sections were mounted, dried and stained in Giemsa solution [16].

Hippocampal volume and principal cell numbers were estimated using Stereolnvestigator 10 software (MBF Bioscience, Williston, VT, USA). The hippocampus including dentate gyrus (DG) and cornu ammonis (CA) were determined in the sections using rat brain atlas of Paxinos and Watson (2007) [33]. DGs were recognised due to horseshoe-shape with small and densely packed neurons. The CA2 region in this study was considered as belong to the $C A 3$ region because the CA2 is very small and the boundaries between these two regions are not detectable. The border between the CA 3 and CA1 is defined by a small transition zone between the two regions (Fig. 1) [21].

\section{Estimation of the volume}

Estimation of total volume of the hippocampus was done using test points on each section (Fig. 2A). The volume was estimated by Cavalieri estimator us- 

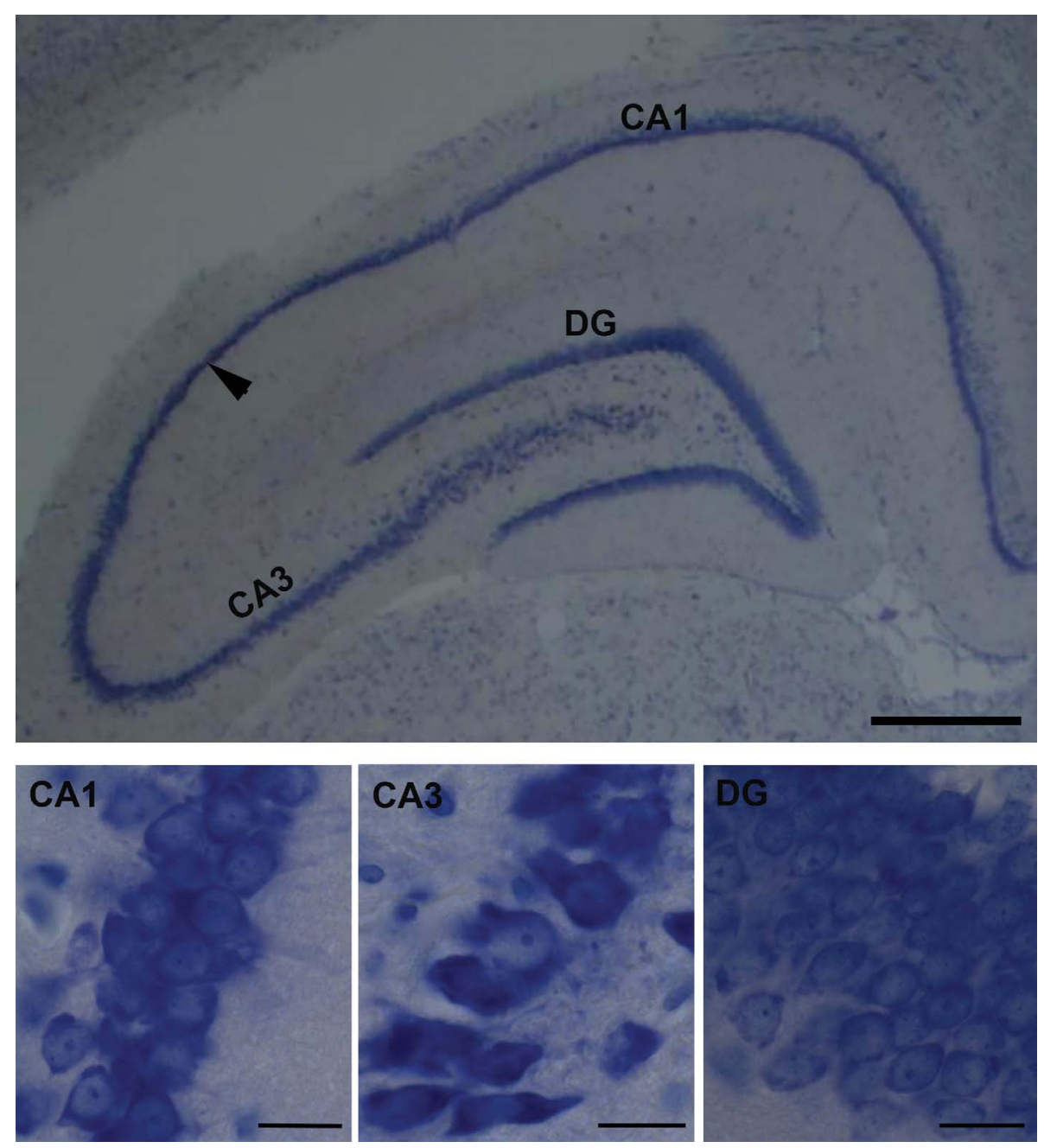

Figure 1. Histological coronal section of the hippocampus (scale bar $=200 \mu \mathrm{m}$ ) with magnification of the CA1, CA3 and dentate gyrus (scale bar $=500 \mu \mathrm{m})$. Arrowhead mark boundary between CA1 and CA3.

ing the following equation [15]: $\mathbf{V}=\Sigma \mathbf{P} \times \mathbf{s s f} \times \mathbf{T} \times$ $x(a / p)$, where $\Sigma P$ is the total number of points hitting the structure; ssf $(1 / 20)$ is the section sampling fraction; $\mathrm{T}(20 \mu \mathrm{m})$ is the section thickness and $\mathrm{a} / \mathrm{p}$ $\left(9 \times 10^{4} \mu \mathrm{m}^{2}\right)$ represents the area per point.

\section{Estimation of the number of neurons}

The optical fractionator was used for number estimation of pyramidal cells and granular cells in CA and DG, respectively. First, the contours of the dentate gyrus and the CA1 and CA3 regions were delineated at low magnification. Then, selected regions were analysed by systematic random sampling at high magnification. A known fraction of the each section was assessed by moving the microscope motorised stage in regular step length in $\mathrm{x}$ and $\mathrm{y}$ directions and applying an unbiased counting frame sized to count the neurons of specific region (Fig. 2B).
For DG, a step length of $180 \mu \mathrm{m}$ and counting frame size of $12 \times 12 \mu \mathrm{m}$ was used, for CA1 a step length of $240 \mu \mathrm{m}$ and frame size of $20 \times 20 \mu \mathrm{m}$, and for CA3 a step length of $190 \mu \mathrm{m}$ and frame size of $24 \times 24$ was applied. The counting frame was focused through $10 \mu \mathrm{m}$ of the section thickness, which corresponds to disector height. Section thickness was measured at every 4-5 sampling location.

The total number of cells in the granular cells (DG) and pyramidal cells (CA1 and CA3) in the left hemisphere was calculated using the following formula $[6,32]-N=1 / \mathrm{SSF} \times 1 / \mathrm{ASF} \times 1 / \mathrm{HSF}^{2} \times \Sigma \mathbf{Q}^{-}$, where $\mathbf{H S F}=\mathbf{h} / \mathbf{t Q}^{-}$for $\mathbf{t Q}^{-}=\sum \mathbf{t}_{\mathbf{i}} \mathbf{q}_{\mathrm{i}}^{-} / \sum \mathbf{q}_{\mathbf{l}^{-}}, \Sigma \mathbf{Q}^{-}$: total count of particles sampled; SSF: the section sample fraction; ASF: the area sample fraction (frame size/ / $x$, y step length); HSF: the height sampling fraction; $\mathrm{h}$ : the dissector height (10 $\mu \mathrm{m}$ in this study); tQ: the number-weighted mean section thickness; $t_{i}$ : the 

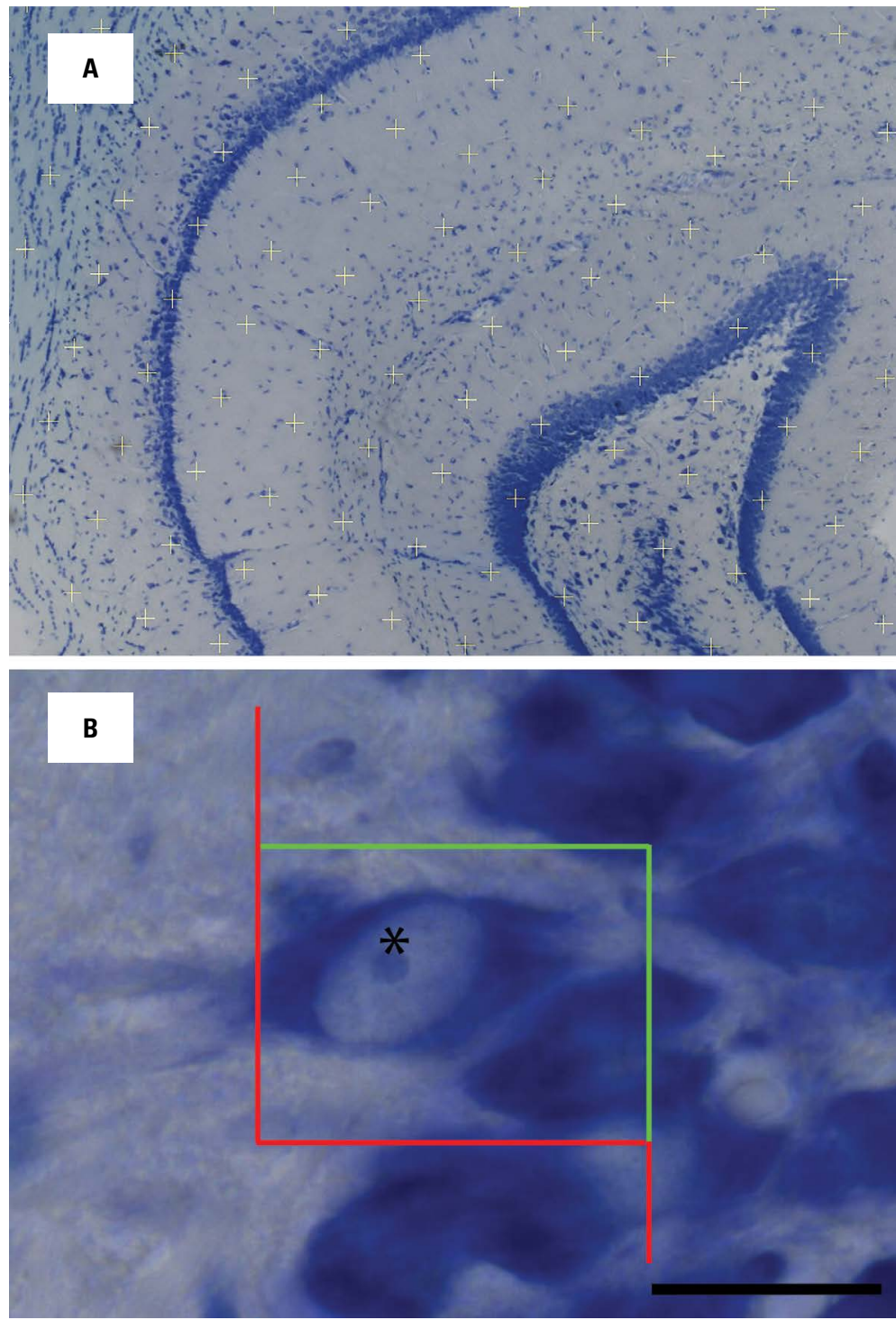

Figure 2. Stereological method for estimating hippocampal volume and neuronal number; $\mathbf{A}$. Example of a point grid on histological section of the hippocampus. The total number of points hitting the whole hippocampus was counted; B. Example of a unbiased counting frame used for optical dissector method. The cells which their nucleolus came into focus within dissector's height if they were completely inside the counting frame or touched the accepted lines (green lines) were counted. Here one neuron (asterisk) was counted (scale bar $=200 \mu \mathrm{m}$ ).

section thickness in the $\mathrm{i}^{\text {th }}$ counting frame with a cell count of $\mathrm{q}_{1}^{-}$in the disector.

\section{Statistical analysis}

The coefficient of error (CE) of the volume and the number estimates was calculated as previously described [13]. T-test was used for statistical analysis. A value of $p<0.05$ was considered significant.

\section{RESULTS}

The results showed that the volume of the hippocampus was significantly decreased after OX treatment compared with the vehicle control group $(p<0.05)$. The related volume of hippocampus in
OX-treated and vehicle control group was $31.84 \pm$ $\pm 1.24 \mathrm{~mm}^{3}$ and $36.95 \pm 3.48 \mathrm{~mm}^{3}$, respectively (Table 1). The number of neurons in DG, CA1 and CA3 did not show any significant difference between the two groups. The neuronal number of DG, CA1 and CA3 in the OX-treated group was estimated to be $8.147 \pm$ $\pm 2.84 \times 10^{5}, 4.257 \pm 0.59 \times 10^{5}$ and $2.133 \pm 0.22$ $\times 10^{5}$, respectively, while the related neurons in vehicle control group accounted $7.36 \pm 1.42 \times 10^{5}, 3.521 \pm$ $\pm 0.54 \times 10^{5}$ and $1.989 \pm 0.46 \times 10^{5}$, respectively (Table 1 ). The $\mathrm{CE}^{2} / \mathrm{CV}^{2}$ ratios (Table 1 ) are typically $>0.5$ indicating that group variances are dominated by the inter-animal differences with only minor contributions of measurement variance to the group variance. 
Table 1. Estimated hippocampal volume and neuron number

\begin{tabular}{|c|c|c|c|c|c|c|c|}
\hline & \multicolumn{3}{|c|}{ OX-treated group } & \multicolumn{3}{|c|}{ Vehicle treated group } & \multirow[t]{2}{*}{$\mathbf{P}$} \\
\hline & Mean \pm SD & CE & CV & Mean \pm SD & CE & CV & \\
\hline Total volume $\left[\mathrm{mm}^{3}\right]$ & $31.84 \pm 1.24^{\mathrm{a}}$ & 0.02 & 0.03 & $36.95 \pm 3.48^{b}$ & 0.02 & 0.09 & 0.01 \\
\hline Granular cell number [105] & $7.36 \pm 1.42$ & 0.11 & 0.19 & $8.147 \pm 2.84$ & 0.11 & 0.34 & 0.69 \\
\hline Pyramidal cell number in CA1 $\left[10^{5}\right]$ & $3.521 \pm 0.54$ & 0.11 & 0.15 & $4.257 \pm 0.59$ & 0.1 & 0.13 & 0.19 \\
\hline Pyramidal cell number in CA3 $\left[10^{5}\right]$ & $1.989 \pm 0.46$ & 0.12 & 0.23 & $2.133 \pm 0.22$ & 0.12 & 0.1 & 0.33 \\
\hline
\end{tabular}

Mean \pm standard deviation (SD) of hippocampal volume and neurons from one hemisphere ( 5 animals in each group) estimates with CE (= SEM/mean; inter-animal coefficient of error) and CV ( $=S D /$ mean; observed inter-animal coefficient of variation). Different superscript letters in the same rows indicate a significant difference, $p<0.05$.

\section{DISCUSSION}

The hippocampus is pivotal for learning and the formation of memory in the brain. Since the hippocampus shows various forms of plasticity, including the formation of new nerve cells in adult animals, it may be affected by the chemotherapeutic drugs leading to cognitive deficit [25].

In the present study, stereological techniques were used for the quantification of volume and number of neurons of the hippocampus following OX treatment in rat. The results of the current experiment demonstrated that treatment with OX caused a reduction in total volume of the hippocampus. Considering that oxaliplatin penetrates the blood brain barrier and accumulates in the brain $[17,18]$, an effect on the hippocampus is plausible and may explain memory impairment and other cognitive dysfunctions that have been found in previous studies using behavioural tests $[9,10,39]$.

Similar to our results, magnetic resonance imaging (MRI) studies showed a reduced hippocampus volume in breast cancer survivors exposed to chemotherapy $[1,3,22]$. In contrast, Yoshikawa et al. [47] found no adverse effects of adjuvant chemotherapy on hippocampal volume in Japanese breast cancer survivors, using MRI. They implied that brain regions other than the hippocampus, such as the prefrontal cortex, might be involved in memory impairment after chemotherapy.

The neuron numbers did not show any significant loss of either granular cells of the DG or pyramidal cells of the CA1 and CA3 following OX treatment in rat. OX has been reported to induce apoptotic pathway in hippocampus with increasing caspase- 3 and caspase-9 [4]. Cyclophosphamide chemotherapy has been suggested to suppress hippocampal neurogenesis and interrupt hippocampal function in mice [45]. Methotrexate also showed inhibition of the formation of immature neurons in the hippocampus [12,44]. It is interesting that although hippocampal neuronal loss has been explained well in Alzheimer diseases, Joelving et al. [20] did not find any significant loss of neuron in Parkinson's disease. Korbo et al. [24] also reported no loss of hippocampal neurons in non-Alzheimer dementia.

It should be mentioned that reduction in the number of neurons is not the only mechanism that affect neuronal function. Structurally, decreasing dendritic branching or losing synapses may impair neuronal function without neuronal loss [1]. Changes in hippocampal transmitters and signal transduction pathways are other mechanisms that may disturb hippocampal function [30, 31]. These findings suggest that cognitive disorders may be associated with a variety of changes that may not necessarily include a change in neuronal cell number [20].

It is important to note that the estimating neuron number based on two-dimensional counting is potentially biased. In our study, the potential bias was avoided by the use of the optical fractionator, which is a combination of fractionator sampling and the optical disector principle. This unbiased stereological method is not influenced by tissue deformation like shrinkage or swelling. Importantly, it is also unaffected by changes in the shape or size of the cells that are being counted. The optical fractionator is the gold-standard method for estimating number of neurons [14, 24].

\section{CONCLUSIONS}

This study is the first description of an effect of oxaliplatin on the rat hippocampus using stereology. In conclusion, the results of the present study showed that OX treatment induces a decrease of hippocampal volume without neuronal loss. These findings might help to clarify the mechanism by which OX affects cognition by crossing the blood-brain barrier and accumulating in cerebrospinal and extracellular fluid in the brain and promote the development of treatment strategies that minimise cognitive side effects. 


\section{Acknowledgements}

The authors would like to thank Prof. David Wolfer and Dr. Lutz Slomianka for their excellent scientific collaboration.

\section{REFERENCES}

1. Apple AC, Ryals AJ, Alpert KI, et al. Subtle hippocampal deformities in breast cancer survivors with reduced episodic memory and self-reported cognitive concerns. Neuroimage Clin. 2017; 14: 685-691, doi: 10.1016/j. nicl.2017.03.004, indexed in Pubmed: 28377882.

2. Barnes CA, Rao G, Houston FP. LTP induction threshold change in old rats at the perforant path--granule cell synapse. Neurobiol Aging. 2000; 21(5): 613-620, doi: 10.1016/ s0197-4580(00)00163-9, indexed in Pubmed: 11016529.

3. Bergouignan $L$, Lefranc JP, Chupin $M$, et al. Breast cancer affects both the hippocampus volume and the episodic autobiographical memory retrieval. PLoS One. 2011; 6(10): e25349, doi: 10.1371/journal.pone.0025349, indexed in Pubmed: 22016764.

4. Bianchi E, Di Cesare Mannelli L, Micheli L, et al. Apoptotic process induced by oxaliplatin in rat hippocampus causes memory impairment. Basic Clin Pharmacol Toxicol. 2017; 120(1): 14-21, doi: 10.1111/bcpt.12629, indexed in Pubmed: 27273873.

5. Di Patre PL, Abbamondi A, Bartolini L, et al. GM1 ganglioside counteracts cholinergic and behavioral deficits induced in the rat by intracerebral injection of vincristine. Eur J Pharmacol. 1989; 162(1): 43-50, doi: 10.1016/00142999(89)90602-x, indexed in Pubmed: 2721563.

6. Dorph-Petersen KA, Nyengaard JR, Gundersen HJ. Tissue shrinkage and unbiased stereological estimation of particle number and size. J Microsc. 2001; 204(Pt 3): 232-246, doi: 10.1046/j.1365-2818.2001.00958.x, indexed in Pubmed: 11903800.

7. Dubois M, Lapinte N, Villier V, et al. Chemotherapy-induced long-term alteration of executive functions and hippocampal cell proliferation: role of glucose as adjuvant. Neuropharmacology. 2014; 79: 234-248, doi: 10.1016/j. neuropharm.2013.11.012, indexed in Pubmed: 24291465.

8. ElBeltagy M, Mustafa S, Umka J, et al. Fluoxetine improves the memory deficits caused by the chemotherapy agent 5-fluorouracil. Behav Brain Res. 2010; 208(1): 112-117, doi: 10.1016/j.bbr.2009.11.017, indexed in Pubmed: 19914299.

9. Fardell JE, Vardy J, Shah JD, et al. Cognitive impairments caused by oxaliplatin and 5-fluorouracil chemotherapy are ameliorated by physical activity. Psychopharmacology (Berl). 2012; 220(1): 183-193, doi: 10.1007/s00213-0112466-2, indexed in Pubmed: 21894483.

10. Fardell JE, Vardy J, Monds LA, et al. The long-term impact of oxaliplatin chemotherapy on rodent cognition and peripheral neuropathy. Behav Brain Res. 2015; 291: 80-88, doi: 10.1016/j.bbr.2015.04.038, indexed in Pubmed: 25934489.

11. Foley JJ, Raffa RB, Walker EA. Effects of chemotherapeutic agents 5-fluorouracil and methotrexate alone and combined in a mouse model of learning and memory. Psychopharmacology (Berl). 2008; 199(4): 527-538, doi: 10.1007/ s00213-008-1175-y, indexed in Pubmed: 18463849.

12. Goncalves MB, Williams EJ, Yip P, et al. The COX-2 inhibitors, meloxicam and nimesulide, suppress neurogenesis in the adult mouse brain. Br J Pharmacol. 2010; 159(5): 1118-1125, doi: 10.1111/j.1476-5381.2009.00618.x, indexed in Pubmed: 20136845.

13. Gundersen HJ, Jensen EB, Kiêu K, et al. The efficiency of systematic sampling in stereology--reconsidered. J Microsc. 1999; 193(Pt 3): 199-211, doi: 10.1046/j.13652818.1999.00457.x, indexed in Pubmed: 10348656.

14. Hosseini-Sharifabad M, Nyengaard JR. Design-based estimation of neuronal number and individual neuronal volume in the rat hippocampus. J Neurosci Methods. 2007; 162(1-2): 206-214, doi: 10.1016/j.jneumeth.2007.01.009, indexed in Pubmed: 17368561.

15. Howard V, Reed MG. Unbiased stereology: three-dimensional measurement in microscopy. BIOS Scientific Publishers, Taylor \& Francis Group, New York 2005.

16. Iñiguez C, Gayoso MJ, Carreres J. A versatile and simple method for staining nervous tissue using Giemsa dye. J Neurosci Methods. 1985; 13(1): 77-86, doi: 10.1016/01650270(85)90045-7, indexed in Pubmed: 3887046.

17. Jacobs SS, Fox E, Dennie C, et al. Plasma and cerebrospinal fluid pharmacokinetics of intravenous oxaliplatin, cisplatin, and carboplatin in nonhuman primates. Clin Cancer Res. 2005; 11(4): 1669-1674, doi: 10.1158/1078-0432. CCR-04-1807, indexed in Pubmed: 15746072.

18. Jacobs S, McCully CL, Murphy RF, et al. Extracellular fluid concentrations of cisplatin, carboplatin, and oxaliplatin in brain, muscle, and blood measured using microdialysis in nonhuman primates. Cancer Chemother Pharmacol. 2010; 65(5): 817-824, doi: 10.1007/s00280-009-1085-7, indexed in Pubmed: 19662415.

19. Janelsins MC, Roscoe JA, Berg MJ, et al. IGF-1 partially restores chemotherapy-induced reductions in neural cell proliferation in adult C57BL/6 mice. Cancer Invest. 2010; 28(5): 544-553, doi: 10.3109/07357900903405942, indexed in Pubmed: 20014946.

20. Joelving FC, Billeskov R, Christensen JR, et al. Hippocampal neuron and glial cell numbers in Parkinson's disease: a stereological study. Hippocampus. 2006; 16(10): 826-833, doi: 10.1002/hipo.20212, indexed in Pubmed: 16941622.

21. Kaae SS, Chen F, Wegener G, et al. Quantitative hippocampal structural changes following electroconvulsive seizure treatment in a rat model of depression. Synapse. 2012; 66(8): 667-676, doi: 10.1002/syn.21553, indexed in Pubmed: 22389166.

22. Kesler S, Janelsins M, Koovakkattu D, et al. Reduced hippocampal volume and verbal memory performance associated with interleukin- 6 and tumor necrosis factor-alpha levels in chemotherapy-treated breast cancer survivors. Brain Behav Immun. 2013; 30 Suppl: S109-S116, doi: 10.1016/j. bbi.2012.05.017, indexed in Pubmed: 22698992.

23. Konat GW, Kraszpulski M, James I, et al. Cognitive dysfunction induced by chronic administration of common cancer chemotherapeutics in rats. Metab Brain Dis. 2008; 23(3): 325-333, doi: 10.1007/s11011-008-9100-y, indexed in Pubmed: 18690526.

24. Korbo L, Amrein I, Lipp HP, et al. No evidence for loss of hippocampal neurons in non-Alzheimer dementia patients. Acta Neurol Scand. 2004; 109(2): 132-139, doi: 10.1034/j.16000404.2003.00182.x, indexed in Pubmed: 14705976.

25. Li J, Li Y, Su H, et al. The influence of environment stimulation on learning and memory function in rats with medication chemotherapy. Annu Int Conf IEEE Eng 
Med Biol Soc. 2018; 2018: 3537-3540, doi: 10.1109/ EMBC.2018.8513084, indexed in Pubmed: 30441142.

26. Li CQ, Liu D, Huang L, et al. Cytosine arabinoside treatment impairs the remote spatial memory function and induces dendritic retraction in the anterior cingulate cortex of rats. Brain Res Bull. 2008; 77(5): 237-240, doi: 10.1016/j. brainresbull.2008.07.010, indexed in Pubmed: 18755251.

27. Liedke PE, Reolon GK, Kilpp B, et al. Systemic administration of doxorubicin impairs aversively motivated memory in rats. Pharmacol Biochem Behav. 2009; 94(2): 239-243, doi: 10.1016/j.pbb.2009.09.001, indexed in Pubmed: 19747935.

28. Lomeli N, Di K, Czerniawski J, et al. Cisplatin-induced mitochondrial dysfunction is associated with impaired cognitive function in rats. Free Radic Biol Med. 2017; 102: 274-286, doi: 10.1016/j.freeradbiomed.2016.11.046, indexed in Pubmed: 27908784.

29. Madhyastha S, Somayaji SN, Rao MS, et al. Hippocampal brain amines in methotrexate-induced learning and memory deficit. Can J Physiol Pharmacol. 2002; 80(11): 1076-1084, doi: 10.1139/y02-135, indexed in Pubmed: 12489927.

30. Marksteiner J, Lechner T, Kaufmann WA, et al. Distribution of chromogranin B-like immunoreactivity in the human hippocampus and its changes in Alzheimer's disease. Acta Neuropathol. 2000; 100(2): 205-212, doi: 10.1007/ s004010000239, indexed in Pubmed: 10963369.

31. Nowakowski C, Kaufmann WA, Adlassnig C, et al. Reduction of chromogranin B-like immunoreactivity in distinct subregions of the hippocampus from individuals with schizophrenia. Schizophr Res. 2002; 58(1): 43-53, doi: 10.1016/s0920-9964(01)00389-9, indexed in Pubmed: 12363389

32. Olesen MV, Needham EK, Pakkenberg B. The optical fractionator technique to estimate cell numbers in a rat model of electroconvulsive therapy. J Vis Exp. 2017(125), doi: 10.3791/55737, indexed in Pubmed: 28715378.

33. Paxinos G, Watson C. The rat brain in stereotaxic coordinates. Elsevier, Amsterdam 2007.

34. Park JH, Chae J, Roh K, et al. Oxaliplatin-Induced Peripheral Neuropathy via TRPA1 Stimulation in Mice Dorsal Root Ganglion Is Correlated with Aluminum Accumulation. PLoS One. 2015; 10(4): e0124875, doi: 10.1371/journal. pone.0124875, indexed in Pubmed: 25928068.

35. Rebert CS, Pryor GT, Frick MS. Effects of vincristine, maytansine, and cis-platinum on behavioral and electrophysiological indices of neurotoxicity in the rat. J Appl Toxicol. 1984; 4(6): 330-338, doi: 10.1002/jat.2550040610, indexed in Pubmed: 6542922.

36. Reiriz AB, Reolon GK, Preissler T, et al. Cancer chemotherapy and cognitive function in rodent models: memory impairment induced by cyclophosphamide in mice. Clin Cancer Res. 2006; 12(16): 5000-5001, doi: 10.1158/10780432.CCR-06-0138, indexed in Pubmed: 16914590.

37. Seigers $R$, Schagen SB, Beerling $W$, et al. Long-lasting suppression of hippocampal cell proliferation and im- paired cognitive performance by methotrexate in the rat. Behav Brain Res. 2008; 186(2): 168-175, doi: 10.1016/j. bbr.2007.08.004, indexed in Pubmed: 17854921.

38. Sprowl JA, Ciarimboli G, Lancaster CS, et al. Oxaliplatin-induced neurotoxicity is dependent on the organic cation transporter OCT2. Proc Natl Acad Sci U S A. 2013; 110(27): 11199-11204, doi: 10.1073/pnas.1305321110, indexed in Pubmed: 23776246.

39. Sharpe MJ, Fardell JE, Vardy J, et al. The chemotherapy agent oxaliplatin impairs the renewal of fear to an extinguished conditioned stimulus in rats. Behav Brain Res. 2012; 227(1): 295-299, doi: 10.1016/j.bbr.2011.11.005, indexed in Pubmed: 22101173.

40. Ueno T, Endo K, Hori K, et al. Assessment of antitumor activity and acute peripheral neuropathy of 1,2-diaminocyclohexane platinum (II)-incorporating micelles (NC-4016). Int J Nanomedicine. 2014; 9: 3005-3012, doi: 10.2147/ IJN.S60564, indexed in Pubmed: 24971011.

41. Vardy J, Tannock I. Cognitive function after chemotherapy in adults with solid tumours. Crit Rev Oncol Hematol. 2007; 63(3): 183-202, doi: 10.1016/j.critrevonc.2007.06.001, indexed in Pubmed: 17678745.

42. Winocur G, Vardy J, Binns MA, et al. The effects of the anti-cancer drugs, methotrexate and 5-fluorouracil, on cognitive function in mice. Pharmacol Biochem Behav. 2006; 85(1): 66-75, doi: 10.1016/j.pbb.2006.07.010, indexed in Pubmed: 16935324.

43. Wafai L, Taher M, Jovanovska V, et al. Effects of oxaliplatin on mouse myenteric neurons and colonic motility. Front Neurosci. 2013; 7: 30, doi: 10.3389/fnins.2013.00030, indexed in Pubmed: 23486839.

44. Yang M, Kim JS, Kim J, et al. Acute treatment with methotrexate induces hippocampal dysfunction in a mouse model of breast cancer. Brain Res Bull. 2012; 89(1-2): 50-56, doi: 10.1016/j. brainresbull.2012.07.003, indexed in Pubmed: 22796103.

45. Yang M, Kim JS, Song MS, et al. Cyclophosphamide impairs hippocampus-dependent learning and memory in adult mice: Possible involvement of hippocampal neurogenesis in chemotherapy-induced memory deficits. Neurobiol Learn Mem. 2010; 93(4): 487-494, doi: 10.1016/j. nlm.2010.01.006, indexed in Pubmed: 20109567.

46. Yanovski JA, Packer RJ, Levine JD, et al. An animal model to detect the neuropsychological toxicity of anticancer agents. Med Pediatr Oncol. 1989; 17(3): 216-221, doi: 10.1002/mpo.2950170309, indexed in Pubmed: 2787469.

47. Yoshikawa E, Matsuoka Y, Inagaki M, et al. No adverse effects of adjuvant chemotherapy on hippocampal volume in Japanese breast cancer survivors. Breast Cancer Res Treat. 2005; 92(1): 81-84, doi: 10.1007/s10549-005-1412-6, indexed in Pubmed: 15980995.

48. Zhou W, Kavelaars A, Heijnen CJ. Metformin prevents cisplatin-induced cognitive impairment and brain damage in mice. PLoS One. 2016; 11(3): e0151890, doi: 10.1371/ journal.pone.0151890, indexed in Pubmed: 27018597. 